\title{
BIMBINGAN KONSELING KLINIS PADA SISWA SMA DI KOTA BEKASI
}

\author{
Sara Sahrazad ${ }^{1}$, Maria Cleopatra ${ }^{2}$ \\ ${ }^{1}$ Program Studi Pendidikan Bimbingan Konseling, FIPPS, Universitas Indraprasta PGRI Jakarta \\ ${ }^{2}$ Program Studi Teknik Informatika, FPTK, Universitas Indraprasta PGRI Jakarta \\ *Penulis Korespodensi : sara.sahrazad@gmail.com ${ }^{1}$, mariacleopatra1313@gmail.com²
}

\begin{abstract}
Abstrak
Kegiatan pengabdian masyarakat ini bertujuan memberikan bimbingan konseling pada siswa yang mengalam kendala belajar dan beberapa permasalahan yang dijumpai dalam keluarga. Metode yang akan dilakukan dalam Kegiatan ini adalah melalui beberapa tahap. Tahap pertama tatap muka, dan demonstrasi. Tahap selanjutnya para peserta diberikan bimbingan belajar dan cara mengatasi masalah yang timbul di kelas dan dirumah. Kegiatan diikuti oleh 37 siswa dari 2 SMA. Hasil kegiatan ini para siswa menjadi lebih nyaman dalam menyampaikan informasi kendala dan hamatan belajar,Guru merasa terbantu, dengan adanya penerapan metode yang dapat meningkatkan hasil belajar disekolah,,bimbingan yang baik dapat memotivasi siswa untuk mengatasi masalah belajar dan para guru dapat memperbaiki pembelajaran dan meningkatkan kompetensi mereka dengan metode yang baik. Kata Kunci : Bimbingan, Klinis, Siswa SMA
\end{abstract}

\begin{abstract}
This community service activity aims to provide counseling guidance to students who experience learning constraints and some problems encountered in the family. The method that will be carried out in this activity is through several stages. The first stage is face to face, and demonstration. The next stage the participants were given tutoring and how to overcome problems that arise in the classroom and at home. The activity was attended by 37 students from 2 high schools. The results of this activity students become more comfortable in conveying information about obstacles and learning constraints, the teacher feels helped, by the application of methods that can improve learning outcomes at school "good guidance can motivate students to overcome learning problems and teachers can improve learning and improve their competency with good methods.
\end{abstract}

Keywords: Guidance, Clinical, High School Students 


\section{Pendahuluan}

Pada pembelajaran saat ini,masih didapati berbagai permasalahan yang timbul karena komunikasi. Dalam hal ini termasuk pengajar, murid dan kepala sekolah. Komunikasi yang baik dapat dilakukan jika guru,murid dan kepala sekolah serta seluruh personil yang berhubungan dengan sekolah saling mengerti ,akan pentingnya komunikasi yang efektif dan baik. Guru atau dosen yang mengajar terkadang tidak mempunyai bakat atau punya keterbatasan yang rendah dalam hal berkomunikasi yang baik dan efektif.

Menurut hasil pengamatan yang dilakukan peneliti melalui observasi kelas dan wawancara dengan guru mata pelajaran bimbingan konseling dan beberapa guru lainya semester genap di SMK Insan Mulia dan SMA Future Gate tahun pelajaran 2017/2018 menunjukkan kurang optimalnya komunikasi antar guru dan siswa. Bedasarkan informasi guru BK di sekolah, perlu adanya pemahaman bersama ,akan pentingna komunikasi yang efektif. Pembelajaran akan kurang maksimal dan perlu penguatan dari pihak sekolah dan pihak lain seperti yayasan ,komite dan yang lainya. Peran serta (keaktifan) guru BK saja,tidaklah cukup dan perlu dibantu dengan bimbingan konseling, bekerjasama dalam memberikan pemahaman komunikasi yang efektif. Wilkerson, K., Pérusse, R., \& Hughes, A. (2013) penelitian tentang konselor sekolah, program bimbingan konseling komprehensif dan prestasi akademik, hasil penelitian menunjukkan dukungan program bimbingan dan koseling komprehensif memiliki kontribusi yang signifikan dalam meningkatkan pretasi siswa ,lebih lanjut ketika pendekatan bimbingan dan konseling perkembangan dipergunakan akan menggabungkan pendekatan yang berorientasi klinis, remidial, dan preventif, (Myrick, 2011:8). Peran para guru juga diharapkan dapat membantu kelancaran proses belajar. Namun dari prapenelitian yang dilakukan oleh tim pelaksana pengabdian masyarakat, ditemukan masih kurang optimalnya pembelajaran di kelas. Masih monoton dan membosankan siswa. Sehingga menurunkan motivasi belajar siswa, disamping kendala yang timbul dari rumah.

Pembelajaran yang dapat menarik perhatian dan membuat semangat siswa,perlu dikembangkan dan diwujudkan. Salah satunya dengan mengurangi kendala belajar yang ada dirumah atau dikelas.

\section{Metode}

Metode yang akan dilakukan dalam Kegiatan ini adalah melalui beberapa tahap :

1. Tatap Muka, yakni pengabdian langsung datang ke lokasi pengabdian untuk memperolah data. Hal ini kami lakukan pada saat menjelang maupun saat Kegiatan berlangsung. Observasi berguna untuk mengetahui kondisi anak-anak di SMA Future gate dan Insan 
Mulia dan menentukan materi Komunikasi. Observasi sangat penting untuk mewujudkan kesuksesan Kegiatan pengabdian masyarakat itu sendiri.

2. Demontrasi, yaitu : tim pengabdi memerikan bimbingan konseling bagi s kepada siswa-siswi SMA Future gate dan Insan Mulia, Jumlah keseluruhan yang ikut pelaksanaan ini sebanyak 38 siswa. Kegiatan akan dilakukan 8 tatap muka agar siswa-siswi SMA Future gate dan Insan Mulia dapat memahami bimbingan yang akan diberikan.

\section{Peserta dan Pembimbing Kegiatan}

1. Peserta Kegiatan

Peserta Kegiatan pengabdian masyarakat pada siswa SMA Future gate dan Insan Mulia kota Bekasi.

2. Pembimbing Kegiatan

Pembimbing dalam Kegiatan ini adalah dosen yang berada dalam program studi teknik industri dan mampu pada bidangnya, berikut tabel 1 mengenai pembimbing Kegiatan.

Tabel 1. Daftar pembimbing pelaksana Kegiatan :

No. Kegiatan Pembimbing

1. Proposal dan Sosialisasi Tim pengabdian Masyarakat

2. Materi Maria Cleopatra

3. Pelaksanaan Demonstrasi Sarah Sahrezad

4. Evaluasi dan Laporan Semua Tim

\section{Hasil dan Pembahasan}

Sekolah Menengah Atas Future gate dan SMK Insan Mulia merupakan sekolah yang menekankan kemandirian dan muatan materi sekolah bernafaskan islam. Siswa pria ada yang tinggal di asrama. Dengan Kegiatan yang padat, membuat tim abdimas, menyesuaikan jadwal dengan Kegiatan sekolah,mulai dari ujian nasional,ekstrakurikuler dan rapat guru dan orang tua murid tentang perpisahah sekolah .Para siswa mendapat informasi tntang Kegiatan abdimas dari guru wali kelas dan kepala sekolah. Sebagian ada bertanya tentang permasalahan elajar di rumah. . Pertemuan awal, tim abdimas memperkenalkan diri dan memberi informasi tentang pentingnya komunikasi yang efektif dalam proses pembelajaran serta Bimbingan Konseling Klinis.

Dari pemasalahan yang ada,tim menemukan $70 \%$ masalah,merupakan masalah belajar dirumah, sedangkan sisanya masalah keluarga dan masalah yang berkaitan dengan masalah ekonomi keluarga. 
Secara umum dapat dirangkum beberapa masalah BK dan solusi beberapa siswa di SMK Insan Mulia:

Tabel 2. Temuan dan saran solusi yang dapat diterapkan

\begin{tabular}{|c|c|c|c|}
\hline No & Nama Siswa & Permasalahan & Saran Solusi \\
\hline 1 & MK & $\begin{array}{lrr}\text { Jarak } & \text { kesekolah } & 5 \\
\text { KM,sering } & \text { telambat } \\
\text { sekolah } & \end{array}$ & $\begin{array}{l}\text { Guru BK } \\
\text { memberikan } \\
\text { nasehat dan } \\
\text { memanggil } \\
\text { kedua orangtua }\end{array}$ \\
\hline 2 & MNB & $\begin{array}{l}\text { Hasil belajar menurun } \\
\text { drastis ,sejak ditinggal } \\
\text { alm.bapak }\end{array}$ & $\begin{array}{l}\text { Dibentuk } \\
\text { kelompok } \\
\text { belajar }\end{array}$ \\
\hline 3 & KLJ & $\begin{array}{l}\text { Sering tidur dikelas, hasil } \\
\text { belajar rendah }\end{array}$ & $\begin{array}{l}\text { Tisur awal dan } \\
\text { memberikan } \\
\text { jadwal belajar } \\
\text { yang } \\
\text { ketatdiawasi } \\
\text { keduaorangtua }\end{array}$ \\
\hline 4 & MKL & Sering gaduh dikelas & $\begin{array}{l}\text { Diberikan } \\
\text { pendekatan } \\
\text {,himbauan }\end{array}$ \\
\hline 5 & HJN & Bolos sekolah & $\begin{array}{l}\text { Dipanggil orang } \\
\text { tua dan } \\
\text { memberikan } \\
\text { solusi dengan } \\
\text { ikut partiipasi } \\
\text { orangtua untuk } \\
\text { mengawasi. }\end{array}$ \\
\hline 6 & $J K L$ & Bertengkar di sekolah & $\begin{array}{l}\text { Dipanggil kedua } \\
\text { orang tua }\end{array}$ \\
\hline 7 & $\mathrm{GH}$ & $\begin{array}{l}\text { Mengejek teman dan } \\
\text { bertengkar fisik }\end{array}$ & $\begin{array}{l}\text { Diberikan } \\
\text { perlakuan ,baik } \\
\text { nasehat dan } \\
\text { hukuman } \\
\text { ringan }\end{array}$ \\
\hline
\end{tabular}


Sesi berikutnya,para guru diberi kesempatan untuk bertanya tentang penggunaan kegiatan,demi peningkatan pembelajaran dan minat belajar siswa yang kadang rendah. ,sebelum diadakan evaluasi para guru juga ikut andil untuk memberikan masukan. Hal ini bersama-sama dikerjakan dengan saling membantu. Para murid dan guru mempunyai niat yag baik ,untuk meningkatkan kompetensi mereka, sehingga jika ada permasalahan dan kendala di sekola dapat diatasi dengan cepat dan tepat. Dapat di rangkum jadwal Kegiatan sebagai `berikut :

Tabel. 3 Jadwal pelaksanaan

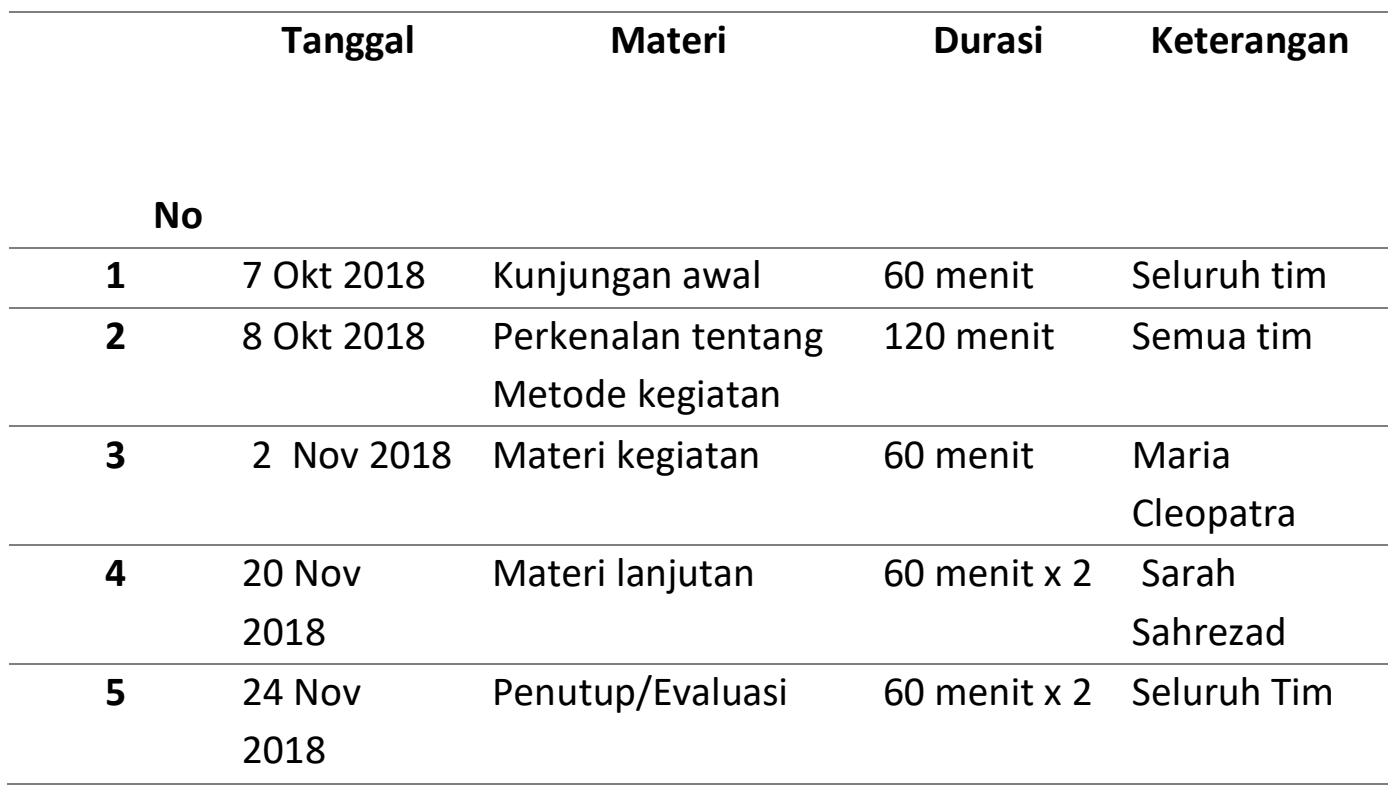

\section{A. Pembahasan dan Hasil Kegiatan}

Kegiatan pengabdian masyarakat di SMA ,memerlukan waktu yang tepat. Tim dapat membantu pembelajaran dengan komunikasi yang efektif dengan baik. Para siswa dapat mempraktekan diluar kelas dengan baik, pada saat tim memberikan beberapa motivasi belajar, beberapa siswa mengutarakan kendala belajar dirumah dan disekolah. 


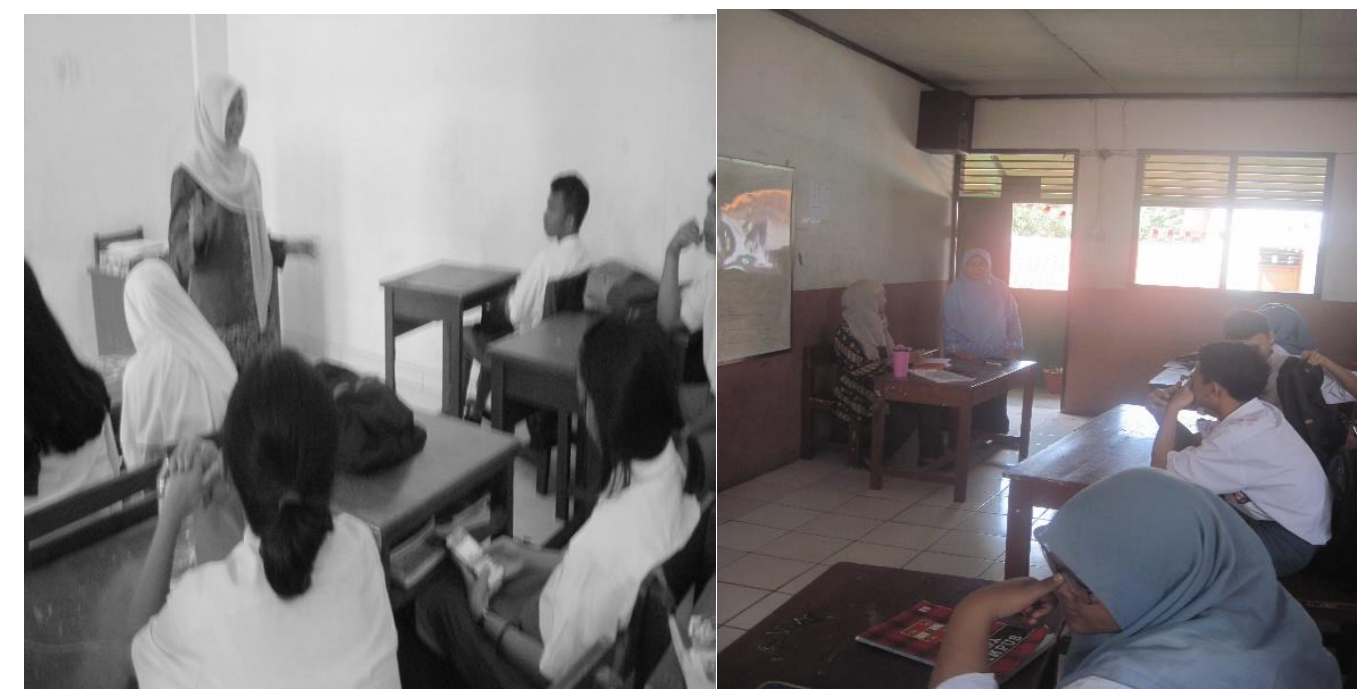

Gambar 1 dan 2. Gambar kegiatan siswa.

Pada gambar 1 dan 2 diatas siswa-siswi latihan mengutarakan pendapat dan kendala belajar. Siswa nampak antusias dalam mengikuti sesi motivasi belajar. Siswa dapat mengutarakan pendapat masing masing kepada teman,guru dan siswa kelas lain.

Pada bimbingan konseling, guru bimbingan konseling memberikan pertanyaan ,kepada para siswa dengan cara bertanya langsung .siswa dapat mengutaran masalah-masalah belajar yang dihadapinya,baik dirumah maupun dikelas. Berikut rangkuman beberapa siswa yang menghadapi kendala pembelajaran, yang di bimbing oleh guru bimbingan Konseling. Di SMK FG:

Tabel. 2

\begin{tabular}{|c|c|c|c|}
\hline No & Siswa & Permasalahan & Solusi dan saran \\
\hline 1 & $\mathrm{BD}, \mathrm{KS}, \mathrm{GI}$ & $\begin{array}{l}\text { "siswa sering } \\
\text { mengantuk } \\
\text { didalam kelas } \\
\text { pada jam belajar" }\end{array}$ & \begin{tabular}{ll} 
Guru memberikan & \multicolumn{2}{c}{ jadwal nonton TV } \\
dan orang tua \\
melakukan \\
pendekatan \\
komunikasi pada \\
siswa
\end{tabular} \\
\hline 2 & CLS,FY,HG,SK & $\begin{array}{l}\text { "Didalam kelas } \\
\text { sering membawa } \\
\text { HP dan telat } \\
\text { masuk sekolah" }\end{array}$ & $\begin{array}{l}\text { Guru BK memanggil } \\
\text { orang tua untuk } \\
\text { berdiskusi bersama } \\
\text { mencari }\end{array}$ \\
\hline
\end{tabular}




\begin{tabular}{|c|c|c|c|}
\hline & & & terbaik \\
\hline 3 & $A G, H A, F G, A D$ & $\begin{array}{l}\text { "Nilai rata rata } \\
\text { pelajaran ujian } \\
\text { nasional dibawah } \\
40 "\end{array}$ & $\begin{array}{l}\text { Guru wali } \\
\text { murid,memberikan } \\
\text { pelajaran tambahan } \\
\text { dan motivasi }\end{array}$ \\
\hline 4 & $\mathrm{DSW}, \mathrm{HI}, \mathrm{DF}$ & $\begin{array}{l}\text { " Tidak mau } \\
\text { mengerjakan } \\
\text { tugas pelajaran" }\end{array}$ & $\begin{array}{l}\text { 'Guru dan orang } \\
\text { tua,bersama-sama } \\
\text { memberikan } \\
\text { dorongan motivasi } \\
\text { dan bimingan belajar. }\end{array}$ \\
\hline 5 & UYH,JK & $\begin{array}{l}\text { Sering telat } \\
\text { masuk } \\
\text { sekolah/pelajaran } \\
\text { awal }\end{array}$ & $\begin{array}{l}\text { Diberikan motivasi } \\
\text { kedisiplinan seta } \\
\text { bimbingan konseling }\end{array}$ \\
\hline 6 & $\mathrm{HS}, \mathrm{MN}$ & $\begin{array}{l}\text { Sering } \\
\text { mengganggu } \\
\text { teman di dalam } \\
\text { kelas }\end{array}$ & $\begin{array}{l}\text { Guru Bimbingan } \\
\text { konseling } \\
\text {,memberikan } \\
\text { bimbingan dan tugas } \\
\text { tambahan.(hukuman) }\end{array}$ \\
\hline
\end{tabular}

Secara umum siswa mengisi angket setelah tim melakukan pedampingan dan mendapatkan gambaran ,seberapa manfaat Kegiatan pengabdian masyarakat yang dilakukan oleh tim. Pertanyaan angket :

1.Apakah dalam pembelajaran anda memerlukan metode yang efektif ?

2.Apakah metode yang efektif sangat penting dalam pembelajaran?

3.Apakah anda dapat mengaplikasikan Metode tersebut yang baik?

4.Apakah BK yang sudah dilaksanakan sangat membantu dalam pembelajaran?

5. Apakah Kegiatan ini diperlukan ,dikemudian hari?

Adapun hasil angket yang diisi oleh 11 guru di sekolah hasilnya sebagai berikut : 


\section{Chart Title}

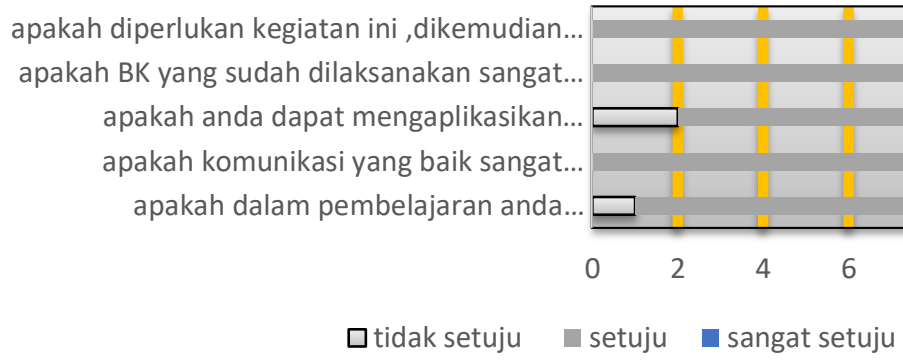

$\square$ tidak setuju $\quad$ setuju $\quad$ sangat setuju

\section{Grafik . 1. Angket pendapat tentang kegiatan Pengabdian Masyarakt}

Pada gambar 3, Nampak para guru sebagian besar setuju ,pelaksanaan pengabdian masyarakat ini, dan mempunyai manfaat yang dapat membantu pembelajaran di kelas

\section{Simpulan}

Peningkatan mutu belajar dengan penerapan kegiatan dan bimbingan konseling merupakan tahapan yang masih panjang. Hal ini dapat diartikan bahwa, program ini hanya tahap awal yang perlu dikembangkan lebih lanjut. Tim berencana untuk melanjutkan pada semester yang akan datang. Bimbingan konseling dapat membantu dan memberikan solusi yang baik bagi sekolah dan dapat disimpulkan sebagai berikut :

a. Para siswa menjadi lebih nyaman dalam menyampaikan informasi kendala dan hamatan belajar

b. Guru merasa terbantu, dengan adanya penerapan metode yang dapat meningkatkan hasil belajar disekolah

c. Bimbingan yang baik dapat memotivasi siswa untuk mengatsi masalah belajar

d. Para guru dapat memperbaiki pembelajaran dan meningkatkan kompetensi mereka dengan metode yang baik.

\section{Saran}

Dari simpulan di atas, kami mengajukan saran dan rekomendasi sebagai berikut :

a. Guru harus meningkatkan profesionalisme, dengan memberikan pembelajarn yang kekinian dalam hal berkomunikasi 
b. Guru hendaknya memberikan pembelajaran kepada siswa -siswi, tanpa membeda bedakan, yang berprestasi lebih ditingkatkan dan bagi siswa - siswi yang kurang agar lebih dibimbing untuk lebih maju.

c. Perkembangan zaman , harusnya diikuti dengan pola didik yang lebih baik.

d. Kerjasama yang baik dan berkesinambungan perlu dilakukan antar lembaga sekolah, baik kepala sekolah, guru, pengawas, orang tua dan siswa - siswi dalam meningkatkan pembelajaran yang baik, efektif dalam menghasilkan pembelajaran yang bermanfaat.

e. Daftar Pustaka

Bhakti, C. P. (2017). Program bimbingan dan konseling komprehensif untuk mengembangkan standar kompetensi siswa. JURKAM: Jurnal Konseling Andi Matappa, 1(2), 131-132.

Riskiyah, R. (2017). Implementasi Permen Dikbud No 111 Tahun 2014 Dan Implikasinya Terhadap Kompetensi Dan Uraian Tugas Guru Bimbingan \& Konseling. Jurnal Pendidikan (Teori dan Praktik), 2(1).

Sunarmintyastuti, L., \& Widiyarto, S. (2019). Pelatihan Pembuatan Prakarya Dalam Rangka Meningkatkat Minat Berwirausaha Siswa Mts. Matappa: Jurnal Pengabdian Kepada Masyarakat, 2(2)

Myrick, Robert D. 2011. Developmental Guidance and Counseling : A Practical Approach Fifth edition. Minneapolis : Educational Media Corporation

Wilkerson, K., Pérusse, R., \& Hughes, A. (2013). Comprehensive school counseling programs and student achievement outcomes: A comparative analysis of RAMP versus non-RAMP schools. Professional School Counseling, 16(3), 172-184. 
Journal of Empowerment Community

Vol. 1 No. 2, September 2019 